\title{
O novo Estatuto DO ESTRANGEIRO \\ E A IMPOSSIBILIDADE DE AQUISIÇÃO DE TERRAS EM REGIÃO DE FRONTEIRA POR ESTRANGEIROS
}

\section{Um novo caso de expulsão}

\section{Priscila Caneparo dos Anjos}

Mestre em Direito das Relações Econômicas Internacionais pela PUC-SP. Especialista em Direito Internacional pela PUC-SP. Advogada.

ÁreA do Direito: Constitucional

RESUMO: A condição jurídica do estrangeiro em solos nacionais delimita-se pelo Estatuto do Estrangeiro - Lei 6.815/1980, ressaltados todos os seus direitos e deveres quando este no Brasil se encontrar. Ocorre que, com a globalização e os movimentos migratórios cada vez mais intensos, o referido diploma legal não mais atende aos reclames da sociedade e, dessa forma, há o projeto do novo Estatuto do Estrangeiro, prevendo novos direitos e obrigações a esse último. Nesse sentido, uma de suas novas proibições é a impossibilidade de aquisição, pelo estrangeiro, de terras em regiões de fronteiras brasileiras, trazendo como consequência maior segurança e completo exercício da soberania ao Estado brasileiro e, ao estrangeiro, caso descumpra tal preceito, a pena de expulsão do pais, uma vez que causa danos à ordem interna brasileira.

Palavras-chave: Novo Estatuto do Estrangeiro Impossibilidade de aquisição em terras fronteiriças - Expulsão do estrangeiro.
Recebido em: 09.08.2011 Aprovado em: 24.08.2011

ABSTRACT: The legal status of foreign nationals in Brazil is delimited by the Statute of Foreigner - Law 6.815/1980. In the Statute are located all rights and duties of foreigners when they are in Brazil. As a result of globalization and the intense migration, this law no longer attend to the claims of society and thus there is a project called ad the New Statute of the Foreign, providing new rights and obligations to them. In this sense, one of its new prohibition is the special restriction on the acquisition of land in border areas. This prohibition seems to bring more security and to exercise the sovereignty. If the foreign breaks this rule, the penalty is the expulsion to guarantee the Brazilian's internal order.

KeYwords: New Statute of Foreign - Special restriction on the acquisition of land in border areas - Expulsion of foreigners. 
SumÁrio: 1. Introdução - 2. A condição jurídica do estrangeiro e o ordenamento brasileiro - 3. Direitos e deveres do estrangeiro em solos nacionais a partir do novo Estatuto do Estrangeiro - 4. A proibição de aquisição de terras em regiões de fronteiras por estrangeiros: 4.1 A importância das fronteiras no Brasil; 4.2 Da aquisição de terras por estrangeiros em solos nacionais; 4.3 As repercussões juridicas da proibição e a consequente expulsão do estrangeiro infrator - 5. Considerações finais - 6 . Referências bibliográficas.

\section{INTRODUÇão}

Em um mundo globalizado, onde as fronteiras demonstram-se cada vez menores, os indivíduos aparentam estar, cada vez mais, sob a égide de uma única cultura, torna-se praticamente impossível supor que um Estado não venha abrigar, em seu território, estrangeiros.

Por mais que seja mera liberalidade do Estado permitir ou não a entrada de diferentes nacionalidades em seus domínios, acaba por ser quase que certa a necessidade de abrir suas portas àqueles cidadãos de terceiros Estados. Em decorrência, deve o Estado estar preparado jurídica, política e socialmente para a presença desses indivíduos.

Em concordância com essa realidade encontra-se o Brasil, que possui em seu ordenamento, desde agosto de 1980, o Estatuto do Estrangeiro, prevendo direitos e deveres a estes indivíduos.

Ocorre que a sociedade mudou e, em decorrência, muitas das necessidades se alteraram, não mais comportando aquele diploma legal. Então, surgiu como projeto ainda, o novo Estatuto do Estrangeiro, prevendo algumas modificações a esses últimos, sendo objeto de análise desse estudo uma delas: a impossibilidade de aquisição, por estrangeiros, de terras em regiões de fronteiras.

Juntamente a essa nova regra, há de serem analisados, para a correta compreensão, seus pontos conexos, quais sejam: as fronteiras no Brasil, a aquisição de terras por estrangeiros e, finalmente, as consequências dessa referida norma.

Assim sendo, deve-se, igualmente, examinar se a sanção para a referida norma, a expulsão, demonstra-se condizente com a realidade e se ela, por si só, torna-se eficaz.

Nesse sentido, esse estudo tem por objetivo final analisar se a impossibilidade de aquisição de terras fronteiriças por estrangeiros e sua pena de expulsão, ambas frutos do novo Estatuto do Estrangeiro, respondem aos reclames da sociedade brasileira.

\section{A CONDIÇÃO JURÍdICA DO ESTRANGEIRO E O ORDENAMENTO BRASILEIRO}

Inicialmente, cabe dizer que a condição jurídica do estrangeiro, em solos nacionais, acompanha todos os reclames de uma sociedade internacional glo- 
balizada, onde não se imagina mais, apenas, que as pessoas permaneçam, por toda sua vida, em um só local.

Nesse sentido, vislumbra-se a necessidade de construção e consolidação de direitos e deveres daqueles que se encontram, seja passageira ou permanentemente, em outro local que não de sua naturalidade.

Acaba por ser facilmente identificável a influência dos direitos de cidadania na condição jurídica do estrangeiro, uma vez que com inúmeras interações entre o local e o global, os indivíduos deixam de se vincularem apenas ao seu território natural, passando de cidadãos nacionais a cidadãos globais, com direitos e deveres de caracteres transnacionais, todos pautados na solidariedade, fraternidade, igualdade e respeito mútuo.

Ocorre que, apesar de toda essa interação, é necessário que, onde um determinado ser se encontre, determine-se sua natureza jurídica e seus direitos e deveres que da sua condição decorrem.

Assim sendo, surge a figura do estrangeiro, podendo ser das mais variadas formas caracterizado, dependendo da natureza de ingresso em um determinado Estado.

Nesse momento, cabe a ressalva de que o Estado é soberano para decidir se aceita ou não a presença de estrangeiros em seu território, mas, caso o faça, é necessário que tenha delimitado seus direitos e deveres. Conforme os entendimentos de Francisco Rezek, nenhum Estado soberano é obrigado, por princípio de direito das gentes, a admitir estrangeiros em seu território, seja em definitivo, seja a título temporário. ${ }^{1}$

Avaliada, então, a arbitrariedade de um determinado Estado no reconhecimento de estrangeiros em seu território, cabe pontuar, nesse momento, o caso brasileiro.

O Brasil admite e reconhece a entrada de pessoas que aqui não nasceram e nem possuem a nacionalidade brasileira em seu território, tendo como princípios básicos dessa relação as determinações do art. 5. ${ }^{\circ}$, caput, da CF ("todos são iguais perante a lei, sem distinção de qualquer natureza, garantindo-se aos brasileiros e aos estrangeiros residentes no País a inviolabilidade do direito à vida, à liberdade, à igualdade, à segurança e à propriedade").

Logicamente, as referidas regras não encontram respaldo absoluto para todas as situações que possam se desenrolar quando da presença do estran-

1. Rezer, Francisco. Direito internacional público: curso elementar. 10. ed. São Paulo: Saraiva, 2005. p. 193. 
geiro em território nacional, sendo que, em detrimento do interesse público, da segurança do Estado, da integridade do território nacional, da distribuição de renda, do acesso à propriedade, da manutenção de empregos, entre outros pontos, há algumas exceções. ${ }^{2}$

Igualmente, como bem pontua Dolinger, ${ }^{3}$ a residência no país, ressaltada no caput do art. $5 .^{\circ}$ da CF, determina que os direitos políticos só valem, coerentemente, aos estrangeiros que, de fato, aqui residem. E, também, entende-se que os estrangeiros residentes no Brasil possuem, em regra, os mesmos direitos e devem observar as mesmas obrigações dos brasileiros considerados natos.

Examina-se a existência de uma lei específica para o tratamento do estrangeiro em solos nacionais, qual seja, a Lei 6.815/1980 (com as devidas alterações da Lei 6.964/1981), conhecida também como Estatuto do Estrangeiro.

Para que seja possível a entrada do estrangeiro em solos nacionais, de acordo com o art. $4 .^{\circ}$ da referida lei, é necessário, via de regra, o porte de visto em seu passaporte - concedido pela autoridade consular ou diplomática brasileira em seu país de origem - que se enquadrará nas seguintes modalidades: de trânsito, turista, temporário, permanente, de cortesia, oficial e diplomático. Caso existam acordos com outros Estados, o Brasil poderá vir a dispensar a exigência de vistos para nacionais desses locais.

Caso o estrangeiro venha a residir regularmente no Brasil, poderá gozar dos direitos civis previstos pela legislação e, caso esteja trabalhando, gozará, igualmente, de todos os direitos trabalhistas. Taxa-se que, em nenhuma hipótese, poderá o estrangeiro adquirir direitos políticos em solos nacionais, não podendo votar e nem ser votado, por força do art. 14 , $\S \S 2 .^{\circ}$ e $3 .^{\circ}, \mathrm{I}, \mathrm{da} \mathrm{CF}$, respectivamente.

Além disso, o estrangeiro, em situações normais, poderá deixar o Brasil quando assim quiser, mas há casos em que há a necessidade da saída compulsória do estrangeiro do território nacional, sendo elencadas, no Estatuto do Estrangeiro, três hipóteses, quais sejam: (a) deportação; (b) expulsão; e (c) extradição.

Na deportação - forma prevista nos arts. 57 a 64 da Lei 6.815/1980 - o estrangeiro incorre em uma entrada irregular em território nacional ou sua estada tornou-se irregular. Não há impossibilidade de regresso ao Brasil quando

2. Gama, Ricardo Rodrigues. Introdução ao direito internacional. Campinas: Bookseller, 2002. p. 110.

3. Dolinger, Jacob. Direito internacional privado: parte geral. 6. ed. Rio de Janeiro: Renovar, 2001. p. 216. 
a situação for regularizada e a seguinte forma compulsória de saída do estrangeiro é realizada por iniciativa das autoridades locais, mais especificamente da própria Polícia Federal.

Vale ser dito que a deportação só será realizada caso o estrangeiro, após receber notificação da autoridade competente para retirar-se, não o faça voluntariamente.

Já na segunda modalidade, na expulsão, disciplinada nos arts. 65 a 75 da Lei 6.815/1980, o estrangeiro fica impossibilitado de regressar ao Estado dependendo, para o seu retorno, da revogação por intermédio de um novo decreto, do decreto de expulsão.

Em concordância com o art. 65 da Lei 6.815/1980, diz-se ser possível a expulsão do estrangeiro que tiver atitudes nocivas à conveniência e aos interesses nacionais, que atentar contra a segurança nacional, contra a ordem política, social, a tranquilidade ou moralidade pública, contra a economia popular, que praticar fraude para entrada ou permanência em solos nacionais, entregar-se à vadiagem ou mendicância ou, ainda, desrespeitar proibições previstas em lei para estrangeiros.

Instaura-se inquérito por intermédio do Ministro da Justiça e a formalização da expulsão depende de decreto advindo da Presidência da República, impossibilitando seu regresso e tornando-o, até mesmo, crime, de acordo com o art. 338 do CP brasileiro. Cabe ressaltar não ser passível de expulsão o estrangeiro que tenha cônjuge brasileiro (não estando separado) ou filho brasileiro sob sua guarda e manutenção econômica, ou ainda, o refugiado que esteja regularmente registrado (excetuando casos que envolvam a segurança nacional ou a ordem pública).

Finalmente, há a figura da extradição, sendo, talvez, a mais séria das formas de saída compulsória do estrangeiro. Nesse instituto, o Estado entrega, para que seja processado ou para a própria execução da pena, o indivíduo acusado ou já culpado por sentença, ao outro Estado que requereu a extradição, cujo qual é competente para julgá-lo ou puni-lo.

De acordo com os entendimentos do Ministério da Justiça, a extradição acaba por materializar-se em um ato de defesa internacional que demonstra colaboração de um Estado para com o outro na repressão de um crime. Mas, ainda assim, lembra-se que a extradição é uma faculdade do Estado, podendo ou não extraditar o sujeito que aqui se encontra ao Estado requerente.

O referido instituto, na lei brasileira, encontra-se descrito nos arts. 76 a 94 da Lei 6.815/1980, não podendo ser concedida, taxativamente, nas seguintes hipóteses do art. 77 da referida Lei: (a) ser o indivíduo brasileiro, excetuando- 
-se aquele que adquiriu a nacionalidade brasileira após a ocorrência do fato que motivou o pedido de extradição; (b) quando a base do pedido não for crime no Brasil ou no Estado requerente; (c) quando o Brasil demonstrar competência para julgar o crime imputado ao extraditando; (d) se a pena imposta pela lei brasileira para o crime for igual ou inferior a um ano; (e) se o extraditando estiver respondendo processo, pelo mesmo fato que motivou o pedido de extradição, ou já tiver sido condenado/absolvido em solos nacionais; (f) extinta a punibilidade, pela prescrição, em concordância com a lei brasileira ou a do Estado requerente; (g) se o crime for político; ou (h) se o extraditando vier a responder, no Estado requerente, a um tribunal ou juízo de exceção.

O pedido de extradição, pelo Estado requerente, será feito por intermédio da via diplomática ou diretamente ao governo e sua apreciação, em solos brasileiros, será feita pelo STF. Aí, então, passará à análise da Presidência da República que dará a palavra final se o indivíduo será ou não entregue ao Estado solicitante.

Examinados tais aspectos, diz-se, ainda, que o Estatuto do Estrangeiro prevê as hipóteses de naturalização do estrangeiro em solos nacionais, das infrações e penalidades por eles cometidas e, também, os direitos e deveres dos estrangeiros que, nesse momento, passam a ser analisados.

\section{DiREITOS E DEVERES dO ESTRANGEIRO EM SOLOS NACIONAIS A PARTIR DO NOVO Estatuto do EstrangeIRO}

Antes mesmo da discussão dos novos rumos dos direitos e deveres dos estrangeiros à luz de seu novo Estatuto, Projeto de Lei ainda em trâmite perante a Câmara dos Deputados Federais, há a necessidade de serem avaliadas tudo aquilo que no Estatuto hoje vigente, no que se refere a tais pontos, é já previsto aos estrangeiros.

Assim, argumenta-se que, como a qualquer estrangeiro, deve o Estado brasileiro garantir os direitos mais essenciais à pessoa humana, quais sejam, o direito à vida, à integridade física, entre outros. Além desses, de acordo com os entendimentos dos arts. 95 a 110 da Lei 6.815/1980, os estrangeiros gozam de direitos e deveres peculiares à sua estada no Brasil.

Primeiramente, o estrangeiro goza de todos os direitos reconhecidos aos brasileiros, devendo, sempre que solicitado por autoridade competente, exibir documento que comprove sua estada legal no Brasil.

Ainda, para exercer atividade remunerada e proceder a matrícula de ensino, o estrangeiro deverá observar as restrições lhe imputadas e não poderá exer- 
cer a atividade caso disponha de visto de turista, de trânsito ou temporário. No caso de portar visto de cortesia, oficial ou diplomático, só poderá exercer atividade remunerada em favor do Estado estrangeiro, organização ou agência internacional de caráter intergovernamental a serviço de seu país, ou governo.

Há, também, algumas vedações expressas ao estrangeiro, elencadas no art. 106 da Lei 6.815/1980 em vigência, quais sejam: (a) ser proprietário, armador ou comandante de navio nacional; (b) ser proprietário, sócio ou acionista de sociedade proprietária de empresa jornalística e de empresas de televisão e de radiodifusão; (c) ser responsável, orientador intelectual ou administrativo das referidas empresas; (d) obter concessão ou autorização para a pesquisa, prospecção, exploração e aproveitamento das jazidas, minas e outros recursos naturais e dos potenciais de energia hidráulica; (e) ser proprietário ou explorador de aeronave brasileira (salvo o disposto na legislação específica); (f) ser corretor de navios, de fundos públicos, leiloeiro e despachante aduaneiro; (g) participar da administração ou representação de sindicato ou associação profissional; (h) ser prático de barras, portos, rios, lagos e canais; (i) possuir, manter ou operar, mesmo que amadoramente, aparelho de radiodifusão, de radiotelegrafia e similar, salvo reciprocidade; $e,(j)$ prestar assistência religiosa às Forças Armadas e auxiliares, bem como aos estabelecimentos de internação coletiva.

Ainda, o estrangeiro não poderá exercer qualquer atividade política ou que tenha ligação com tal, e nem interferir nos negócios públicos brasileiros. Pontua-se que, para os estrangeiros advindos de Portugal, a Lei estabelece algumas brechas no que tange às proibições previstas aos estrangeiros.

No que tange aos direitos, poderão os estrangeiros associar-se para fins culturais, religiosos, recreativos, beneficentes ou de assistência, além de poderem participar de reuniões comemorativas de datas nacionais.

Por mais que o Estatuto do Estrangeiro em vigor elenque direitos e deveres aos estrangeiros, vê-se a necessidade de uma atualização de tal diploma legal, uma vez que, introduzido no ordenamento jurídico em agosto de 1980, tal instrumento não acompanha mais os reclames da sociedade, que em muito se alterou, especialmente devido à globalização e aos movimentos migratórios cada vez mais presentes.

Em decorrência, desenvolveu-se o PL 5.655/2009 (aqui chamado de novo Estatuto do Estrangeiro), que prevê a substituição da Lei 6.815/1980 por essa em pauta. O referido projeto ainda não foi votado, mas, ainda assim, levantou muitas questões ao debate e, por mais que se encontre aos moldes da Lei que hoje se encontra em vigor, traz consigo algumas significativas alterações à condição do estrangeiro. 
Em concordância com seus termos, destaca-se a possibilidade de facilitação da entrada de imigrantes no país, em concordância com a imagem brasileira no exterior, onde é visto como um Estado aberto à imigração, além de já ter sua lei sobre refugiados considerada, pela própria Organização das Nações Unidas - ONU, como modelo a todo o mundo.

Além disso, as principais inovações repousam em tais questões: (a) necessidade de autorização prévia para a atuação de imigrantes em regiões consideradas estratégicas, como a Amazônia Legal e áreas ocupadas por índios, quilombolas ou outras comunidades tradicionais, sob pena de constituir infração administrativa; (b) proibição do estrangeiro de possuir empresa de vigilância, conjuntamente às proibições de propriedade de empresas jornalísticas e de exploração de recursos minerais e hidráulicos; (c) proibição do estrangeiro de possuir terras em regiões de fronteira brasileira; (d) possibilidade de extradição de brasileiro naturalizado caso se envolva com o tráfico de drogas; (e) permissão para que os estrangeiros possam participar da administração de sindicatos, de associações profissionais e de entidades fiscalizadoras do exercício de profissões regulamentadas; (f) extinção do visto de trânsito; (g) união, em um único instituto, dos vistos de turismo e de negócios; (h) criação da categoria de visto "para tratamento de saúde", extensiva a um acompanhante, concedido por até um ano, prorrogável pelo período que durar o tratamento (realizado na rede privada); (i) possibilidade dos estudantes estrangeiros em exercerem atividades remuneradas, mediante autorização do Ministério do Trabalho; (j) vítimas do tráfico de pessoas que no Brasil se encontram poderão ter residência temporária por até um ano, sendo que, caso a vítima colabore com a investigação, poderá haver prorrogação do período ou, até mesmo, ter autorização para permanência; (k) ampliação dos casos em que não será concedida a extradição; e (l) as infrações às normas do novo Estatuto do Estrangeiro poderão ser punidas com multa de até $\mathrm{R} \$ 100$ mil, podendo o valor ser duplicado em caso de reincidência, cominadas com a expulsão, entre outras tantas alterações.

Acredita-se que as novas previsões elencadas pelo referido projeto fazem com que o ordenamento jurídico brasileiro, no que tange à questão dos estrangeiros, venha acompanhar os reclames advindos da sociedade que se modifica, hoje, muito mais rapidamente que quando do desenvolvimento do Estatuto do Estrangeiro que se encontra em vigor.

Logicamente, para que suas disposições sejam aplicadas de maneira coerente e eficazmente, há a indiscutível necessidade sobre o debate dos novos institutos que acompanham o novo Estatuto do Estrangeiro e, nesse sentido, destina-se esse estudo, nesse momento, ao exame da nova proibição do estrangeiro de possuir terras em regiões de fronteira brasileira. 


\section{A PROIBIÇÃO DE AQUISIÇÃO DE TERRAS EM REGIÕES DE FRONTEIRAS POR ESTRANGEIROS}

Tendo em vista que o novo Estatuto do Estrangeiro prevê, em seu art. 7.', VIII, como fruto de uma de suas inovações, a proibição de aquisição de terras em regiões fronteiriças por estrangeiros, necessário se demonstra o estudo dos motivos para a referida proibição e, igualmente, quais as determinações legais que decorrem dessa nova previsão.

Assim sendo, indispensável se demonstra um primeiro exame sobre a questão das próprias fronteiras no Brasil, conjugando-se, posteriormente, à aquisição de terras nacionais por estrangeiros e, também, às consequentes implicações da referida proibição. Então, passa-se à investigação de tais assuntos.

\subsection{A importância das fronteiras no Brasil}

As fronteiras nacionais vão muito além de meras delimitações geográficas a um determinado Estado: são fenômenos complexos, que influenciam não apenas a geografia de um determinado local, mas também a política, a sociedade e a economia. São elas quem, sem dúvidas, determinam até onde o Estado poderá exercer sua soberania, sendo que a demarcação e a indicação de suas fronteiras é direito e dever desse ente.

Assim, pode-se dizer que, constitucionalmente (art. 20, § 2. ${ }^{\circ}$, da CF), a zona de fronteira é a faixa de até 150 quilômetros de largura, ao longo das fronteiras terrestres, considerada como fundamental para a defesa do território nacional brasileiro. ${ }^{4}$ Como bem afirma José Cretella Júnior, o fundamento da criação da faixa de fronteira, em nosso direito, é tríplice, resumindo-se nos desideratos expressos com três vocábulos: segurança nacional, progresso e nacionalização. ${ }^{5}$

Nesse entendimento, indiscutível se demonstra a necessidade de uma vigilância constante na imensa zona limítrofe brasileira, com postos militares de observação, núcleos populacionais de brasileiros e auxílio específico às determinadas regiões, visando a correspondência com os valores nacionais.

4. O art. $1 .^{\circ}$ da Lei 6.634/1979, que dispõe sobre a faixa de fronteira, estabelece: "é considerada área indispensável à Segurança Nacional a faixa interna de $150 \mathrm{Km}$ (cento e cinquenta quilômetros) de largura, paralela à linha divisória terrestre do território nacional, que será designada como Faixa de Fronteira".

5. Cretella Júnior, José. Comentários à Constituição brasileira de 1988. Rio de Janeiro: Forense Universitária, 1991. vol. 3, p. 1269. 
Aponta-se que as fronteiras têm, ainda, uma importância exacerbada ao Brasil na consolidação e proteção de seu próprio território, tendo em vista que, em decorrência da vasta amplitude territorial brasileira, as fronteiras acabam por merecer destaque especial na afirmação da própria soberania do Estado.

Valoriza-se, ainda, que as fronteiras têm, segundo os entendimentos de Celso D. de Albuquerque Mello, ${ }^{6}$ uma tríplice importância na vida internacional: (a) é um 'fator de paz' (em regra geral está regulamentada nos tratados de paz); (b) 'sinal de independência'; (c) 'elemento de segurança' (Rousseau).

Assim sendo, em concordância com os interesses nacionais, poderão ser desenvolvidas leis que prevejam modos de utilização e, até mesmo, proibições para as terras localizadas nessas regiões fronteiriças. Como bem afirma Manoel de Oliveira Franco Sobrinho, "compete à lei que venha a regulamentar o preceito, clarear situações e relações jurídicas, sobre concessão de terras ou vias de comunicação (...)" ${ }^{7}$

Assim sendo, de acordo com os ensinamentos acima expostos, chega-se à conclusão que a faixa de fronteira, segundo sua natureza jurídica, pode ser considerada como bem de uso especial da União, bem do domínio indisponível da União, afetada a serviço público federal relevante, a de defesa do país contra o inimigo externo. Ainda assim, há direito de propriedade nas regiões fronteiriças, mas tal direito deve ser exercido em concordância com os termos das leis que o regulamentam.

Em concordância, as terras que em regiões de fronteiras se encontram são áreas de proteção especial do Estado, tendo em vista os termos do art. 20, § 2. ${ }^{\circ}$, da CF, sendo intransmissíveis para fins de aquisição da posse e exploração indefinida, dependem, para tal, que o titular do domínio tenha o consentimento prévio do Conselho de Segurança Nacional.

Finalmente, registra-se que o interesse do Brasil é extremo, pois conta com 15.719 quilômetros de fronteiras terrestres, correspondendo cerca de $28 \%$ do território nacional. Assim há, de fato, a necessidade de o Brasil proteger, de maneira sólida e eficaz, suas fronteiras contra toda e qualquer forma de aquisição ou posse de propriedades de terceiros Estados, podendo estes estarem, em uma determinada situação, materializados até mesmo na figura de indivíduos estrangeiros.

6. Mello, Celso D. de Albuquerque. Curso de direito internacional público. 3. ed. Rio de Janeiro: Freitas Bastos Ed., 1971. p. 505.

7. Franco Sobrinho, Manoel de Oliveira. Comentários à Constituição. Rio de Janeiro: Freitas Bastos Ed., 1991. p. 359. 


\subsection{Da aquisição de terras por estrangeiros em solos nacionais}

A aquisição de terras brasileiras por estrangeiros pode ser considerada uma prática constante, contando com determinadas leis que a regulamentam.

Primeiramente, nesse sentido, aponta-se que, em concordância com dados do Instituto Nacional de Colonização e Reforma Agrária - Incra, de 2010, os estrangeiros têm a posse de aproximadamente 4,35 milhões de hectares de terras no Brasil, distribuídas em 3.689 municípios localizados, especialmente, nos Estados de Mato Grosso, Mato Grosso do Sul e São Paulo.

Tendo em vista a grande parcela territorial em posse dos estrangeiros, indispensável se faz a existência de uma legislação robusta que atenda a um controle fundiário efetivo. Atualmente, existem algumas leis ordinárias que regulam o controle das terras por estrangeiros, quais sejam: a Lei 5.709/1971 e a Lei 8.629/1993.

No que se refere à Lei 5.709/1971, especifica-se que os estrangeiros não podem adquirir imóveis com área superior a 50 módulos de exploração indefinida, em área contínua ou descontínua (as aquisições de área superior a 100 módulos para pessoa jurídica e 50 para pessoa física dependem de autorização do Congresso Nacional, conforme disposto no art. 23, § 2..$^{\circ}$, da Lei 8.629/1993). Estabelece, ainda, que apenas $1 / 4$ das terras de cada município pode estar na posse de estrangeiros e que aqueles que possuem a mesma nacionalidade só podem possuir, conjuntamente, até $40 \%$ do percentual aqui descrito (1/10 da área do município). Exige, também, que os Cartórios de Registros de Imóveis remetam, trimestralmente, o histórico das aquisições rurais por pessoas estrangeiras.

Debate-se, também, que para a aquisição de propriedade em área rural os estrangeiros deverão respeitar as terras em áreas de fronteira, uma vez que estão impossibilitados de as adquirirem, conforme a seguir será analisado.

Em decorrência dessa investigação, conclui-se que a legislação que hoje existe não consegue, por si só, controlar toda a porção fundiária brasileira e muito menos atender, de fato, as imposições para a aquisição de terras por estrangeiros. Tendo em vista que, com os movimentos migratórios, dia após dia, acentuados pela globalização, necessário se demonstra que o ordenamento brasileiro venha suprir as novas necessidades da sociedade.

Nesse panorama existem hoje, em tramitação, alguns novos projetos de lei que sugerem a alteração das normas que hoje se aplicam à aquisição de terras por estrangeiros. Os projetos de lei são os seguintes: (a) PL 7.407/2006 (ex-Deputado Carlos Souza; estende à posse de terra por estrangeiros às mesmas exigências previstas na Lei 5.709/1971 para a aquisição); (b) PL 2.289/2007 
(Deputado Beto Faro; pessoas físicas ou jurídicas estrangeiras não poderão adquirir nem arrendar imóveis rurais com mais de 35 módulos fiscais, ou com área superior a 2,5 mil hectares); (c) PL 2.376/2007 (Deputado Carlos Alberto Canuto; proíbe a compra de terra destinada à plantação de matéria-prima para biocombustíveis); (d) PL 3.483/2008 (Deputado Vanessa Grazziotin; limita a extensão do imóvel rural adquirido por empresas estrangeiras a 50 módulos fiscais ou 2,5 mil hectares); (e) PL 4.240/2008 (Deputado Antonio Carlos Mendes Thame; empresas brasileiras com maioria do capital estrangeiro estariam sujeitas às mesmas regras das estrangeiras para aquisição de terras e propõe a diminuição para $25 \%$ a área que pessoas da mesma nacionalidade podem possuir de um determinado município); e o (f) PL 5.655/2009 já mencionado (Executivo; substituição do Estatuto do Estrangeiro pelo novo Estatuto do Estrangeiro, com as alterações já discorridas nesse trabalho). ${ }^{8}$

Sintetiza-se, assim, a existência de uma regulamentação para a aquisição de terras por estrangeiros no Brasil, mas ainda assim são normas que não atendem a todos os reclames da sociedade. Vislumbra-se que as mudanças a serem implementadas pelo novo Estatuto do Estrangeiro tendem a ser extremamente benéficas a ambos os interessados, quais sejam, o Estado brasileiro e os próprios estrangeiros.

No ponto de interesse a esse estudo, para o Brasil, a proibição de aquisição de terras por estrangeiros em regiões de fronteiras tende a proteger, primordialmente, sua integridade territorial e sua segurança.

Dessa maneira, examinam-se, nesse momento, as principais consequências jurídicas frutos dessa futura nova proibição.

\subsection{As repercussões jurídicas da proibição e a consequente expulsão do estrangeiro infrator}

Em um primeiro momento, deve-se atinar que as repercussões jurídicas da proibição de aquisição de terras pelos estrangeiros em áreas de fronteiras no Brasil incidem em dois âmbitos, quais sejam: ao próprio Estado e, também, para o próprio estrangeiro sujeito da norma proibitiva.

Adentrando aos aspectos relativos ao Estado, entende-se que essa proibição traz consigo, determinantemente, zonas de maiores seguranças e incidência da própria soberania nacional.

8. Câmara pode restringir a venda de terras para estrangeiros. Disponível em: [www.observatorioeco.com.br/camara-pode-restringir-a-venda-de-terras-para-estrangeiros/]. Acesso em: 09.08.2011. 
Correlacionado à segurança, pode-se dizer que essa será maior tendo em vista que o Estado terá o controle de quem irá ser proprietário das terras em regiões de fronteiras. Assim, podendo apenas seus nacionais adquiri-las, a fiscalização tende a ser mais intensa, uma vez que o Brasil terá o dever e o direito legal, caso algum ilícito ali ocorra por parte dos adquirentes nacionais, de julgá-los. Além disso, a segurança nas regiões fronteiriças é um problema que já se alastra por muitos anos em solos brasileiros, especialmente pela falta de uma fiscalização efetiva - talvez por faltarem agentes, tendo em vista a enorme faixa territorial que corresponde às fronteiras brasileiras - e, igualmente, por ser porta de entrada de muitas rotas de tráfico de drogas, armas e pessoas. Indiscutivelmente, a presença de proprietários de terras estrangeiros nessa região dificultaria ainda mais a consolidação da segurança nessas áreas.

Ao Estado, a proibição em questão traduz, ainda, a possibilidade de maior incidência de sua soberania em seu próprio território. Explica-se: muitas vezes, mesmo que em um mundo globalizado, a forte presença do estrangeiro causa a impressão de que outros Estados exercem, em uma determinada área, maiores influências que o próprio Estado na região em que se encontra. Especialmente em regiões de fronteiras, a presença de estrangeiros torna-se sobremaneira complexa para o próprio exercício da soberania estatal, sendo que há o risco concreto de que nacionais dos Estados que fazem divisa com o Brasil, por exemplo, venham adquirir essas terras fronteiriças e acabem por demandarem essas terras a esses outros Estados. ${ }^{9}$ Indiscutivelmente, tendo em vista esses pontos, a proibição tem sua razão de ser.

Se a proibição traz consequências subjetivas ao Estado brasileiro, já para o estrangeiro a situação se faz clara e objetiva com o novo Estatuto do Estrangeiro: estando presente a supracitada proibição no art. $7 .^{\circ}$, VIII, desse diploma legal, a sanção, igualmente, encontra-se presente em seu art. $149, \mathrm{XVI},{ }^{10}$ prevendo a expulsão caso o estrangeiro venha infringir o primeiro artigo.

Em decorrência, cabe indagar se essa sanção é apropriada para o estrangeiro infrator de tal norma.

Assim, mais uma vez, valoriza-se a expulsão como sendo o modo coativo de retirar o estrangeiro do território nacional por delito ou infração ou atos que

9. O maior exemplo real que se vislumbra é a fronteira entre Brasil e Paraguai, onde, em alguns pontos, pela falta de fiscalização, não se sabe se as terras são efetivamente brasileiras ou paraguaias, dependendo, de fato, dos indivíduos que ali habitam.

10. Art. 149 do PL 5.655/2009. "Constitui infração administrativa:

(...)

XVI - infringir o disposto nos arts. 7. ' e 8. : Sanção - expulsão". 
o tornem inconveniente, ${ }^{11}$ sendo que, sem dúvidas, o estrangeiro que venha a agir dessa maneira merece a pena de expulsão, especialmente pelo fato de perturbar a ordem interna do Estado.

Além disso, cabe determinar se essa hipótese preenche, de fato, os princípios próprios do Direito brasileiro, presentes no instituto da expulsão: sem margem para questionamentos, quando o estrangeiro infringe a regra que não permite adquirir propriedades brasileiras em regiões de fronteira está, claramente, atentando contra a segurança, contra a ordem política, jurídica e social, atendendo, então, aos requisitos para que a expulsão se demonstre cabível ao caso.

Argumenta-se, ainda, que o poder de expulsão do estrangeiro é discricionariedade do próprio Estado, sendo manifestação de sua própria soberania. E é mediante esse entendimento, conjugado aos prejuízos que a aquisição de terras fronteiriças por estrangeiros pode trazer ao Estado que se considera, primeiramente, a proibição extremamente adequada à realidade brasileira e, também, a expulsão como sanção das mais eficazes para aquele estrangeiro que vier a infringir a norma, quando esta entrar em vigor.

\section{Considerações Finais}

Tendo em vista todo o exposto nesse estudo, algumas conclusões merecem ser aqui tecidas.

A primeira delas refere-se ao fato de que o estrangeiro, em solos brasileiros, é reconhecido como sujeito de direitos e deveres, tanto que, para tal, além de contar com preceitos fundamentais, tem o seu próprio conjunto de regras, nomeados como Estatuto do Estrangeiro. Nesse estão elencados, de maneira ampla, seus direitos, deveres e, também, modos de entrada e saída, podendo, ainda, caso incorra em uma das modalidades, formas de saída compulsória, quais sejam: (a) deportação, (b) expulsão e (c) extradição.

Ocorre que, de fato, o referido Estatuto, datado de 1980, não mais comporta todas as necessidades da sociedade e, assim sendo, já se encontra em trâmite nos órgãos brasileiros a adoção do novo Estatuto do Estrangeiro, contendo algumas alterações para esse último, sendo que, nesse trabalho, focou-se na impossibilidade de aquisição de terras em região de fronteira por estrangeiros.

De tal forma, faz-se indispensável compreender que as fronteiras de um determinado Estado são essenciais para a sua segurança e, igualmente, para o

11. Silva, José Afonso da. Curso de direito constitucional positivo. 20. ed. São Paulo: Malheiros, 2002. p. 341. 
exercício de sua soberania, justificando, então, essa nova modalidade de proibição aos estrangeiros.

Além disso, a sanção para aquele estrangeiro que incorrer nesse ilícito acaba por ser a expulsão, justificada pelo fato de que tal atitude traz consigo uma perturbação da ordem interna do Estado brasileiro, não cabendo alternativa senão que a própria expulsão desse indivíduo.

Finalmente, conclui-se, em termos gerais, que o novo Estatuto do Estrangeiro vem, de fato, acompanhar as mudanças da sociedade brasileira e que a impossibilidade da aquisição, por estrangeiros, de terras em regiões fronteiriças - com a eventual sanção de expulsão - valoriza, sem margens para dúvidas, a própria segurança jurídica, política, social e econômica do Estado brasileiro, além de garantir a sua soberania não apenas dentro de seus limites, mas também nesses próprios.

\section{REFERÊNCIAS BIBLIOGRÁFICAS}

Cretella Júnior, José. Comentários à Constituição brasileira de 1988. Rio de Janeiro: Forense Universitária, 1991. vol. 3.

Dolinger, Jacob. Direito internacional privado: parte geral. 6. ed. Rio de Janeiro: Renovar, 2001.

Franco Sobrinho, Manoel de Oliveira. Comentários à Constituição. Rio de Janeiro: Freitas Bastos Ed., 1991.

GAmA, Ricardo Rodrigues. Introdução ao direito internacional. Campinas: Bookseller, 2002.

Mello, Celso D. de Albuquerque. Curso de direito internacional público. 3. ed. Rio de Janeiro: Freitas Bastos Ed., 1971.

ObservatóRio ECo. Câmara pode restringir a venda de terras para estrangeiros. Disponível em: [www.observatorioeco.com.br/camara-pode-restringir-a-vendade-terras-para-estrangeiros/]. Acesso em: 09.08.2011.

Rezer, José Francisco. Direito internacional público: curso elementar. 10. ed. São Paulo: Saraiva, 2005.

Silva, José Afonso da. Curso de direito constitucional positivo. 20. ed. São Paulo: Malheiros, 2002. 


\section{Pesouisas do EdiTORIAL}

\section{Veja também Doutrina}

- Da aquisição de imóvel rural por estrangeiro uma introdução, de Geraldo Cezar Torres Carpes - RDI 16/22;

- Escorço histórico das terras particulares, de Marcos Afonso Borges - RDPriv 19/176;

- 0 regime jurídico da propriedade imóvel no Brasil: do Descobrimento ao Código Civil de 2002, de José Carlos de Oliveira e Odemilson Roberto Castro Fassa - RDI 53/68; e

- Registro de imóveis - Aquisições de imóveis rurais por pessoas jurídicas brasileiras com participação majoritária estrangeira - Necessidade de observância das restrições constantes da Lei 5.709/1971 também para empresas, de Gilson Dipp - RDCl69/379. 